\title{
Mortality Risk Factors Among Hospitalized Children with Severe Pertussis.
}

\section{Tingting Shi}

Guangzhou Medical University

\section{Ling Wang}

Guangzhou Medical University

\section{Shuling Du}

Guangzhou Medical University

Huifeng Fan

Guangzhou Medical University

Minhua Yu

Guangzhou Medical University

\section{Tao Ding}

Guangzhou Medical University

\section{Xuehua Xu}

Guangzhou Medical University

Dongwei Zhang

Guangzhou Medical University

\section{Li Huang}

Guangzhou Medical University

gen lu ( $\sim$ lugen5663330@sina.com )

Guangzhou Medical University

\section{Research article}

Keywords: children, pertussis, pediatric intensive care unit, risk factor

Posted Date: February 19th, 2021

DOI: https://doi.org/10.21203/rs.3.rs-251733/v1

License: (9) This work is licensed under a Creative Commons Attribution 4.0 International License. Read Full License 


\section{Abstract}

Background: Some children hospitalized for severe pertussis infection require intensive care; moreover, some children die because of disease deterioration alone or in combination with other complications. The purpose of this study was to identify mortality risk factors among hospitalized children with severe pertussis.

Methods: This study evaluated the medical records of 144 hospitalized children with severe

pertussis at the Guangzhou Women and Children's Medical Center between January 2016 and December 2019.

Results: The median age of patients was 2 months (IQR, $1-4$ months), with $90.1 \%$ of the patients aged $<6$ months and $56.9 \%$ of the patients aged $<3$ months. A total of 13 patients died, and the mortality of severe pertussis was $34.2 \%$, with patients younger than 6 weeks accounting for $76.9 \%$ of the deaths. On multivariate analysis, the independent risk factors for death were WBC $>70.0 \times 10^{9} / \mathrm{L}$ (odds ratio [OR], 230.66; $95 \%$ confidence interval $[\mathrm{Cl}], 5.16-10319.09 \mathrm{P}=0.005)$ and pulmonary hypertension $(\mathrm{PH})(\mathrm{OR}$, $323.29 ; 95 \% \mathrm{Cl}, 16.01-6529.42 ; \mathrm{P}<0.001)$.

Conclusion: Severe pertussis mainly occurred in children aged $<3$ months. The mortality of severe pertussis was $34.2 \%$, with patients younger than 6 weeks accounting for the majority of the deaths. We recommend the first dose of diphtheria-tetanus-pertussis (DTP) should be advanced to the age of 2 months or even 6 weeks. The presence of a WBC $>70.0 \times 10^{9} / \mathrm{L}$ and $\mathrm{PH}$ were the prognostic variables independently associated with death.

\section{Background}

Pertussis is a highly contagious acute respiratory infection disease that is one of the main causes of infectious disease-related mortality in children [1]. Since the introduction of universal infant and childhood pertussis vaccination in the 1940s in the world, the incidence of pertussis has decreased more than $80 \%$ [2]. However, during the last two decades, pertussis infections have re-emerged worldwide. The WHO estimated that pertussis affects nearly 24 million children aged $<5$ years each year and causes 160 700 deaths in this age group, with the mortality of $4 \%[1,3]$. In a study of infants, the mortality was $70 \%$ and higher in infants younger than 6 weeks (84\%) [4]. In China, 30027 children were diagnosed with pertussis in 2019, and the morbidity of pertussis was lower than that in other countries (21.5/million) [5]. The mortality of pertussis in China is not very clear. This may be due to the limitations of the laboratory tests in China, and it does not reflect the actual incidence.

In this study, we analysed 144 hospitalized paediatric patients with pertussis, including 38 patients with severe pertussis who were admitted to the paediatric intensive care unit (PICU) or neonatal intensive care unit (NICU). The purpose of this study was to identify the mortality risk factors in hospitalized children 
with severe pertussis. This information may be beneficial to effectively prevent and to institute management strategies early for severe cases.

\section{Methods}

\section{Study design}

This study included 144 patients with pertussis who were admitted to Guangzhou Women and Children's Medical Center between January 2016 and December 2019. These patients had tested respiratory tract specimens and were found to be positive for Bordetella pertussis. The patients were selected by identifying respiratory samples (nasopharyngeal secretions) positive for B. pertussis in polymerase chain reaction (PCR). All patients underwent an indirect immunofluorescence virus test of nasopharyngeal secretions during the acute phase of the disease. Blood, sputum and/or bronchoalveolar lavage (BAL) cultures were used to identify bacterial infections, Mycoplasma pneumoniae or fungal infections. All patients also underwent a chest X-ray examination, and some of them underwent high-resolution tomography (HRCT) based on the extensive lesions found on the chest X-ray examination. Patients with incomplete clinical data were excluded from this study.

This study was approved by the Ethics Committee of Guangzhou Women and Children's Medical Centre, Guangzhou Medical University.The study was performed according to the ethical guidelines of the Declaration of Helsinki (7th revision)

\section{Data Collection}

For each patient, data on demographics; clinical presentation; contact history; comorbidities; prematurity, including gestational age and birth weight); vaccination history; time of hospital and PICU/NICU admissions; laboratory findings; microbiological and radiological findings; treatments, including type of medicine used, type of respiratory support and type of life support (exchange blood transfusion, continuous renal replacement therapy (CRRT), extracorporeal membrane oxygenation (ECMO) and inhalation of nitric oxide (NO)); and outcomes were collected. Contact history was defined as a household or close contact who had a preceding cough prior to the patient. Vaccination history was obtained from the vaccination records for each child. Severe pertussis was defined on the criteria of severe pertussis in the American in 2013[6]: All children from 0 to 18 years of age with laboratory confirmed (PCR and/or positive culture) pertussis were eligible for enrolment if they had a PICU stay of at least 24 hours or died. Hyperleukocytosis was defined as $\mathrm{WBC} \geq 50 \times 10^{9} / \mathrm{L}$. Pulmonary hypertension $(\mathrm{PH})$ was defined on the basis of the diagnosis and treatment of PH of the European Society of Cardiology (ESC) and the European Respiratory Society (ERS) [7]. Our patients were considered to have PH based on the judgement of the echocardiography $(\mathrm{ECHO})$ results. No patients underwent cardiac catheterization to judge the $\mathrm{PH}$, because of their young ages and the severity of the illness. Septic shock was defined according to the 
International Pediatric Sepsis Consensus Conference criteria [8]. Acute Respiratory Distress Syndrome (ARDS) is defined by the standards of the Pediatric Acute Lung Injury Consensus Conference criteria [9].

\section{Statistical analysis}

A total of 144 children diagnosed with pertussis in Guangzhou Women and Children's Medical Center from 2016 to 2019 were included. Categorical data were presented as frequency with the corresponding percentage, and continuous data were presented as median with the interquartile range (IQR). The $\chi 2$ or Fisher exact test was used to determine the associations between the categorical variables and pertussis. To determine the independent contribution of each variable to the case outcomes, multivariable logistic regression models were performed. A binary outcome variable was generated that coded for whether the child was a survivor or non-survivor. All analyses were completed using statistical software R Version 3.6.1, and the significance level of all tests was determined at $p<0.05$.

\section{Results}

\section{Demographics and baseline characteristics}

Over the 4-year period, 150 hospitalized patients had a respiratory specimen positive for $B$. pertussis, including 38 patients admitted to the ICU and 13 patients who died. Six patients were not enrolled in this study because of being discharged against medical advice. Of the 144 hospitalized patients enrolled, the demographics and baseline characteristics of patients are shown in Table 1; 47.9\% (69/144) were boys and $52.1 \%(75 / 144)$ were girls, with ages ranging from 3 days to 4 years. The median age was 2 months (IQR, $1-4$ months), with $90.1 \%(130 / 144)$ of the patients aged $<6$ months and $56.9 \%(82 / 144)$ aged $<3$ months, and most of the deaths were in patients $₫ 3$ months $(92.3 \%, 12 / 13)$ as shown in Fig. 1 . In all, $11.8 \%(17 / 144)$ of patients had premature birth and $9.0 \%$ (13/144) of patients had low birth weight. A positive contact history was present in $72.2 \%(104 / 144)$ of patients. All the patients had pertussis vaccine records; $70.8 \%$ (102/144) of patients were unvaccinated for pertussis, with $56.9 \%(82 / 144)$ of the patients aged < 3 months, and 29.2\% (42/144) patients had pertussis vaccination, including $18.8 \%$ $(27 / 144)$ of patients receiving one dose, $6.9 \%$ (10/144) two doses and 3.5\% (5/144) three doses. Of the 144 patients enrolled in the study, only eight patients had comorbid conditions, including chronic lung disease, abnormality in airways and neurologic disorders. Annual pertussis rates and annual pertussis deaths are shown in Fig. 2. 
Table 1

Demographics and baseline characteristics of 144 hospitalized children with pertussis

\begin{tabular}{|c|c|c|c|c|}
\hline \multirow[t]{3}{*}{ Characteristics } & Total & Survivors & Deaths & \multirow[t]{3}{*}{ P-value } \\
\hline & $N=144$ & $N=131$ & $N=13$ & \\
\hline & Number & Number & Number & \\
\hline \multicolumn{5}{|l|}{ Demographics } \\
\hline Male gender & 69 & 63 & 6 & 1.000 \\
\hline Age distribution & & & & $<0.001$ \\
\hline \6 weeks & 28 & 18 & 10 & \\
\hline 6 weeks to 2.9 months & 54 & 52 & 2 & \\
\hline 3 months to 5.9 months & 48 & 47 & 1 & \\
\hline 6 months to 11.9 months & 10 & 10 & 0 & \\
\hline 12 months to 3 years & 2 & 2 & 0 & \\
\hline$\geq 3$ years & 2 & 2 & 0 & \\
\hline Prematurity conditions & 6 & 4 & 2 & 0.091 \\
\hline gestational age & & & & 0.594 \\
\hline$\geq 37$ weeks & 127 & 116 & 11 & \\
\hline 32 weeks to 36.9 weeks & 11 & 10 & 1 & \\
\hline 28 weeks to 31.9 weeks & 6 & 5 & 1 & \\
\hline$\nabla 28$ weeks & 0 & 0 & 0 & \\
\hline birth weight & & & & 0.004 \\
\hline$\geq 2500 \mathrm{~g}$ & 131 & 122 & 9 & \\
\hline $1500 \mathrm{~g}$ to $2499 \mathrm{~g}$ & 10 & 8 & 2 & \\
\hline $1000 \mathrm{~g}$ to $1499 \mathrm{~g}$ & 2 & 0 & 2 & \\
\hline$\otimes 1000 \mathrm{~g}$ & 1 & 1 & 0 & \\
\hline Positive contact history & 104 & 92 & 12 & 0.112 \\
\hline Vaccination history & & & & 0.186 \\
\hline any dose & 102 & 89 & 13 & \\
\hline 1 dose & 27 & 27 & 0 & \\
\hline
\end{tabular}




\begin{tabular}{|lllll|}
\hline Characteristics & Total & Survivors & Deaths & P-value \\
\cline { 2 - 4 } & $\mathbf{N}=\mathbf{1 4 4}$ & $\mathbf{N}=\mathbf{1 3 1}$ & $\mathbf{N = 1 3}$ & \\
\cline { 2 - 4 } & Number & Number & Number & \\
\cline { 1 - 4 } 2 doses & 10 & 10 & 0 & \\
\cline { 1 - 4 } 3 doses & 5 & 5 & 0 & \multirow{2}{*}{0.540} \\
\hline Underlying co-morbid conditions & 8 & 7 & 1 & \\
\hline
\end{tabular}

\section{Clinical Characteristics And Complications}

Cough $(97.9 \%, 141 / 144)$ was the most common symptom in our study, and of these patients, $53.5 \%$ $(77 / 144)$ had a whoop and $78.5 \%(113 / 144)$ had facial congestion, followed by cyanosis $(45.1 \%$, $65 / 155)$, fever $(40.3 \%, 46 / 144)$ and shortness of breath or increased work of breathing $(27.8 \%, 40 / 144)$. The median duration of cough was 13 days on admission (IQR, 7.25-20 days). The most common complication of pertussis was pneumonia $(70.1 \%, 101 / 144)$, followed by respiratory failure $(24.3 \%$, $35 / 144)$, septic shock $(10.4 \%, 15 / 144)$, pleural effusion $(9.7 \%, 14 / 144)$ and $\mathrm{PH}(9.0 \%, 13 / 144)$. The abnormal clinical symptoms, physical examination findings and complications are presented in Table 2 . 
Table 2

Clinical characteristics and complications of 144 hospitalized children with pertussis

\begin{tabular}{|c|c|c|c|c|}
\hline \multirow[t]{3}{*}{ Characteristics } & Total & Survivors & Deaths & \multirow{3}{*}{$\begin{array}{l}\mathrm{P} \text { - } \\
\text { value }\end{array}$} \\
\hline & $N=144$ & $N=131$ & $N=13$ & \\
\hline & Number & Number & Number & \\
\hline \multicolumn{5}{|l|}{ Clinical symptoms } \\
\hline Cough & 141 & 130 & 11 & 0.022 \\
\hline Facial congestion & 113 & 105 & 8 & 0.229 \\
\hline Whoop & 77 & 67 & 10 & 0.088 \\
\hline Cough $\geq 14$ days & 71 & 70 & 1 & 0.002 \\
\hline Cyanosis & 65 & 54 & 11 & 0.003 \\
\hline Fever & 46 & 37 & 9 & 0.004 \\
\hline Axillary temperature $\geq 38.5^{\circ} \mathrm{C}$ & 23 & 17 & 6 & 0.007 \\
\hline Fever $\geq 5$ days & 8 & 8 & 0 & 1.000 \\
\hline Shortness of breath & 40 & 28 & 12 & $<.001$ \\
\hline Fatigue with feeding & 39 & 28 & 11 & $\begin{array}{l}< \\
0.001\end{array}$ \\
\hline Vomiting/diarrhea & 26 & 26 & 0 & 0.126 \\
\hline Altered sensorium & 18 & 10 & 8 & $<.001$ \\
\hline Seizures & 17 & 12 & 5 & 0.008 \\
\hline Apnea & 6 & 4 & 2 & 0.092 \\
\hline \multicolumn{5}{|l|}{ Physical exam findings } \\
\hline Crackles & 66 & 54 & 12 & 0.001 \\
\hline Wheezing & 33 & 27 & 6 & 0.075 \\
\hline Oxygen saturation $<90 \%$ & 31 & 20 & 11 & $\begin{array}{l}< \\
0.001\end{array}$ \\
\hline $\begin{array}{l}\text { Heart rate }>180 / \min (\leq 1 \text { years }) \\
\text { or }>160 / \min (\llbracket 1 \text { year })\end{array}$ & 29 & 18 & 11 & $\begin{array}{l}< \\
0.001\end{array}$ \\
\hline $\begin{array}{l}\text { Respiratory rate }>70 / \min (\leq 1 \text { years }) \text { or }>60 / \min (\rrbracket 1 \\
\text { year) }\end{array}$ & 15 & 5 & 10 & $<.001$ \\
\hline
\end{tabular}




\begin{tabular}{|c|c|c|c|c|}
\hline \multirow[t]{3}{*}{ Characteristics } & Total & Survivors & Deaths & \multirow{3}{*}{$\begin{array}{l}\mathrm{P}- \\
\text { value }\end{array}$} \\
\hline & $N=144$ & $N=131$ & $N=13$ & \\
\hline & Number & Number & Number & \\
\hline Capillary refilling time(CRT) $\otimes 2 \mathrm{~s}$ & 15 & 4 & 11 & $\begin{array}{l}<.001 \\
0.001\end{array}$ \\
\hline Decreased breath sounds & 3 & 3 & 0 & 1.000 \\
\hline \multicolumn{5}{|l|}{ Complications } \\
\hline Pneumonia & 101 & 88 & 13 & 0.010 \\
\hline Respiratory failure & 35 & 22 & 13 & $\begin{array}{l}< \\
0.001\end{array}$ \\
\hline Septic shock & 15 & 5 & 10 & $\begin{array}{l}< \\
0.001\end{array}$ \\
\hline Pleural effusion & 14 & 10 & 4 & 0.024 \\
\hline Pulmonary hypertension & 13 & 1 & 12 & $\begin{array}{l}< \\
0.001\end{array}$ \\
\hline Toxic encephalopathy & 7 & 3 & 4 & 0.001 \\
\hline ARDS & 6 & 0 & 6 & $\begin{array}{l}< \\
0.001\end{array}$ \\
\hline Acute renal failure & 6 & 1 & 5 & $\begin{array}{l}<.001 \\
0.001\end{array}$ \\
\hline Heart failure & 4 & 1 & 3 & 0.002 \\
\hline Pneumorrhagia & 3 & 1 & 2 & 0.022 \\
\hline
\end{tabular}

\section{Laboratory, Radiological And Microbiological Findings}

The abnormal laboratory, radiological and microbiological findings are presented in Table 3. Of the 144 patients, 79.1\%(114/144) had varying degrees of increased white blood cell (WBC) counts and absolute lymphocyte counts, including $13.2 \%$ (19/144) having hyperleukocytosis (WBC $₫ 50.0 \times 10^{9} / \mathrm{L}$ ), with $4.9 \%$ $(7 / 144)$ of patients with WBC $870.0 \times 10^{9} / \mathrm{L}$. Chest radiographic examination results mostly exhibited diffuse infiltration in both lungs. The patients who died tended to present with more severe infection on radiography (Fig. 3). The most common finding on HRCT was consolidation. Some severe patients presented severe consolidation on HRCT (Fig. 4). The other main chest imaging finding was pleural effusion (10.4\%, 15/144); 9.0\% (13/144) of patients were considered to have PH based on the ECHO results, of which most were in the death group $(92.3 \%, 12 / 13)$, and $46.2 \%(6 / 13)$ of the patients who died had severe PH. Among the 144 patients, besides B. pertussis, another causative agent (defined as a 
coinfection) was detected in $69.4 \%(100 / 144)$ of the cases, with bacterial coinfections accounting for $26.4 \%$ (38/144), M. pneumoniae coinfections for $9.7 \%$ (14/144), Chlamydia pneumoniae coinfections for $3.5 \%(5 / 144)$, and viral coinfections for $29.9 \%(43 / 144)$. Of the bacterial coinfection cases, Klebsiella pneumoniae $(6.9 \%, 10 / 144)$ and Streptococcus pneumoniae $(6.9 \%, 10 / 144)$ were the predominant typical bacteria isolated in children with $B$. pertussis infection. The most common viral pathogens isolated were respiratory syncytial virus $(16.0 \%, 23 / 144)$ and rhinovirus $(6.9 \%, 10 / 144)$. 
Table 3

The laboratory, radiological findings, and pathogenies of 144 hospitalized children with pertussis

\begin{tabular}{|c|c|c|c|c|}
\hline \multirow[t]{3}{*}{ Characteristics } & Total & Survivors & Deaths & \multirow[t]{3}{*}{ P-value } \\
\hline & $N=144$ & $N=131$ & $N=13$ & \\
\hline & Number & Number & Number & \\
\hline \multicolumn{5}{|l|}{ Laboratory index } \\
\hline $\mathrm{PO}_{2}<60 \mathrm{mmHg}$ & 32 & 27 & 5 & 0.260 \\
\hline $\mathrm{PCO}_{2}>50 \mathrm{mmHg}$ & 35 & 28 & 7 & 0.024 \\
\hline Abnormal WBC & & & & $<0.001$ \\
\hline WBC $₫ 30.0 \times 10^{\wedge} 9 / \mathrm{L}$ & 93 & 92 & 1 & \\
\hline WBC $30.0-50.0 \times 10^{\wedge} 9 / \mathrm{L}$ & 32 & 31 & 1 & \\
\hline WBC $50.0-70.0 \times 10^{\wedge} 9 / \mathrm{L}$ & 12 & 7 & 5 & \\
\hline$W B C>70.0 \times 10^{\wedge} 9 / L$ & 7 & 1 & 6 & \\
\hline Absolute lymphocyte count $>20 \times 10^{\wedge} 9 / \mathrm{L}$ & 44 & 34 & 10 & $<0.001$ \\
\hline Hemoglobin $<80 \mathrm{~g} / \mathrm{L}$ & 14 & 10 & 4 & 0.024 \\
\hline C-reactive protein $>30 \mathrm{mg} / \mathrm{L}$ & 34 & 26 & 8 & 0.002 \\
\hline Serum albumin $<35 \mathrm{~g} / \mathrm{L}$ & 27 & 21 & 6 & 0.023 \\
\hline Lactate dehydrogenase $>500 \mathrm{U} / \mathrm{L}$ & 14 & 8 & 6 & $<0.001$ \\
\hline $\mathrm{APTT}>50 \mathrm{~s}$ & 9 & 4 & 5 & $<0.001$ \\
\hline Aspartate aminotransferase $>100 \mathrm{U} / \mathrm{L}$ & 7 & 4 & 3 & 0.017 \\
\hline Creatine kinase-MB fraction $>100 \mathrm{U} / \mathrm{L}$ & 4 & 3 & 1 & 0.318 \\
\hline Creatinine $>62 \mathrm{mg} / \mathrm{d}$ & 3 & 0 & 3 & 0.001 \\
\hline Alanine aminotransferase $>100 \mathrm{U} / \mathrm{L}$ & 2 & 1 & 1 & 0.173 \\
\hline \multicolumn{5}{|l|}{ Radiological finding } \\
\hline \multicolumn{5}{|l|}{ X-ray } \\
\hline Trachitis & 49 & 49 & 0 & 0.005 \\
\hline Pneumonia & 101 & 88 & 13 & 0.010 \\
\hline Pleural effusion & 15 & 10 & 5 & 0.003 \\
\hline Pneumothorax & 2 & 2 & 0 & 1.000 \\
\hline
\end{tabular}




\begin{tabular}{|c|c|c|c|c|}
\hline \multirow[t]{3}{*}{ Characteristics } & Total & Survivors & Deaths & \multirow[t]{3}{*}{ P-value } \\
\hline & $N=144$ & $N=131$ & $N=13$ & \\
\hline & Number & Number & Number & \\
\hline Echocardiography (ECHO) & & & & $<0.001$ \\
\hline Low pulmonary hypertension & 2 & 0 & 2 & \\
\hline Intermediate pulmonary hypertension & 5 & 0 & 5 & \\
\hline High pulmonary hypertension & 6 & 1 & 5 & \\
\hline \multicolumn{5}{|l|}{ Co-infections } \\
\hline Pertussis -Virus & 43 & 42 & 1 & 0.109 \\
\hline Respiratory syncytial virus & 23 & 23 & 0 & 0.129 \\
\hline Rhinovirus & 10 & 10 & 0 & 0.600 \\
\hline FA & 6 & 5 & 1 & 0.439 \\
\hline Parainfluenza & 4 & 4 & 0 & 1.000 \\
\hline Adenovirus & 0 & 0 & 0 & 1.000 \\
\hline Pertussis -Bacteria & 38 & 31 & 7 & 0.043 \\
\hline Klebsiella pneumoniae & 10 & 7 & 3 & 0.058 \\
\hline Staphylococcus aureus & 10 & 9 & 1 & 1.000 \\
\hline Haemophilus influenzae & 7 & 5 & 2 & 0.122 \\
\hline Streptococcus pneumoniae & 4 & 3 & 1 & 0.318 \\
\hline Pseudomonas aeruginosa & 3 & 3 & 0 & 1.000 \\
\hline Escherichia coli & 2 & 2 & 0 & 1.000 \\
\hline Acinetobacter baumannii & 1 & 1 & 0 & 1.000 \\
\hline Moraxella catarrhalis & 1 & 1 & 0 & 1.000 \\
\hline Pertussis -Mycoplasma pneumoniae & 14 & 11 & 3 & 0.117 \\
\hline Pertussis - Chlamydia pneumoniae & 5 & 4 & 1 & 0.381 \\
\hline
\end{tabular}

\section{Treatment And Outcome}

Of the 144 patients with $B$. pertussis infection, $38(26.4 \%, 38 / 144)$ patients were admitted to the PICU $(19.4 \%, 28 / 144)$ and NICU $(6.9 \%, 10 / 144) ; 13(9.0 \%, 13 / 144)$ patients died, with $8(5.5 \%, 8 / 144)$ patients 
doing so in the PICU and $5(3.5 \%, 5 / 144)$ in the NICU. The mortality of severe pertussis in the PICU/NICU was $34.2 \%$ (13/38), with patients younger than 6 weeks accounting for $76.9 \%(10 / 13)$ of the deaths. Additionally, 22.2\% (32/144) patients needed oxygen and 24.3\% (35/144) patients needed assisted ventilation, including mechanical ventilation in $20.1 \%$ (29/144) and non-invasive ventilation in $4.2 \%$ (6/144), of whom $10.4 \%$ (15/144) needed assisted ventilation for $>7$ days. The median length of hospitalization was 13 days (IQR, 8.0-19.0 days). The median length of the PICU or NICU stay was 8.5 days (IQR, 2.0-18.0 days). Table 4 shows the treatment of patients as follows: $97.2 \%$ (140/144) patients received macrolide treatments. Most of the patients $(86.8 \%, 125 / 144)$ received macrolide treatments $>7$ days from the onset of symptoms. Of the patients, $24.3 \%$ (35/144) received immunoglobulin therapy. Additionally, 7.6\% (11/144) of patients underwent exchange blood transfusion, $4.2 \%(6 / 144)$ of patients underwent CRRT, and 2.8\% (4/144) of patients received inhalation of NO. 
Table 4

Treatments of 144 hospitalized children with pertussis

\begin{tabular}{|c|c|c|c|c|}
\hline \multirow[t]{3}{*}{ Characteristics } & Total & Survivors & Deaths & \multirow[t]{3}{*}{ P-value } \\
\hline & $N=144$ & $N=131$ & $N=13$ & \\
\hline & Number & Number & Number & \\
\hline \multicolumn{5}{|l|}{ Macrolide treatments } \\
\hline No use & 4 & 3 & 1 & \multirow[t]{4}{*}{0.001} \\
\hline$\otimes 7$ days after the onset of symptoms & 15 & 10 & 5 & \\
\hline $7-14$ days after the onset of symptoms & 64 & 58 & 6 & \\
\hline$\bigotimes 14$ days after the onset of symptoms & 61 & 60 & 1 & \\
\hline Azithromycin & 118 & 108 & 10 & 0.704 \\
\hline Erythromycin & 28 & 24 & 4 & 0.281 \\
\hline Corticosteroid therapy & 24 & 17 & 7 & 0.001 \\
\hline Immunoglobulin therapy & 35 & 31 & 4 & 0.518 \\
\hline \multicolumn{5}{|l|}{ Respiratory support treatments } \\
\hline Oxygen & 32 & 32 & 0 & 0.038 \\
\hline Non-invasive ventilation & 6 & 5 & 1 & 0.439 \\
\hline Need for conventional Mechanical ventilation & 18 & 9 & 9 & $<0.001$ \\
\hline Need for High-frequency ventilation & 11 & 8 & 3 & 0.062 \\
\hline The length of Mechanical ventilation $>7$ days & 15 & 13 & 2 & 0.627 \\
\hline \multicolumn{5}{|l|}{ Life support treatments } \\
\hline Exchange blood transfusion & 11 & 8 & 3 & 0.062 \\
\hline CRRT & 6 & 3 & 3 & 0.010 \\
\hline inhalation of NO & 4 & 0 & 4 & $<0.001$ \\
\hline ECMO & 2 & 1 & 1 & 0.173 \\
\hline
\end{tabular}

\section{Mortality Risk Factors In Hospitalized Children With Severe Pertussis}

Univariate analysis of mortality risk factors in hospitalized children with severe pertussis are shown in Table 1, Table 2, Table 3 and Table 4. Table 1 shows the demographics and baseline characteristics of 
the patients (all $\mathrm{P}<0.05$ ). The host factors associated with death were younger age and lower birth weight. Table 2 presents the clinical characteristics and complications associated with death, which were cyanosis, oxygen saturation $<90 \%, \mathrm{PH}$, septic shock and so on (all $\mathrm{P}<0.05$ ). Table 3 shows that the factors related to the death of patients and laboratory and radiological findings, and pathogenesis include WBC $>70.0 \times 10^{9} / \mathrm{L}$, absolute lymphocyte count $>20 \times 10^{9} / \mathrm{L}$, more severe infiltrations on chest radiography, etc. (all $\mathrm{P}<0.05$ ). Table 4 shows that the factors related to the death of patients and treatment include the need for mechanical ventilation, inhalation of NO, etc. (all $\mathrm{P}<0.05$ ).

Multivariate analysis of mortality risk factors in hospitalized children with severe pertussis are shown in Table 5. In the multivariate analysis, the independent risk factors for death were WBC $>70.0 \times 10^{9} / \mathrm{L}$ (odds ratio [OR], 230.66; 95\% confidence interval [Cl], 5.16-10319.09 $\mathrm{P}=0.005)$ and $\mathrm{PH}(\mathrm{OR}, 323.29 ; 95 \% \mathrm{Cl}$, 16.01-6529.42; $\mathrm{P}<0.001)$.

Table 5

Risk Factors for deaths of 144 hospitalized children with pertussis on Multivariate Analysis

\begin{tabular}{|c|c|c|c|c|c|}
\hline \multirow[b]{2}{*}{ Variables } & \multirow[t]{2}{*}{$\beta$} & \multirow[t]{2}{*}{$\mathbf{P}$} & \multirow[t]{2}{*}{ OR } & \multicolumn{2}{|c|}{ OR $95 \% \mathrm{Cl}$} \\
\hline & & & & Lower & Upper \\
\hline Pulmonary hypertension & 5.7785 & $<0.001$ & 323.29 & 16.01 & 6529.42 \\
\hline WBC & & 0.03 & & & \\
\hline WBC $30.0-50.0 \times 10^{\wedge} 9 / \mathrm{L}$ & 0.6555 & 0.735 & 1.93 & 0.04 & 85.15 \\
\hline WBC $50.0-70.0 \times 10^{\wedge} 9 / \mathrm{L}$ & 2.3441 & 0.195 & 10.42 & 0.3 & 361.22 \\
\hline$W B C>70.0 \times 10^{\wedge} 9 / L$ & 5.4410 & 0.005 & 230.66 & 5.16 & 10319.09 \\
\hline$W B C<30.0 \times 10^{\wedge} 9 / L$ & & & & referen & $e=1$ \\
\hline
\end{tabular}

\section{Discussion}

According to the previous literature, infants have higher rates of pertussis, hospitalizations, complications, and mortality than any other age group [10]. In the present study, pertussis mainly occurred in children aged $<6$ months, especially those aged $<3$ months, which is in line with previous reports[10,11], and most of the patients were unvaccinated with regard to diphtheria-tetanus-pertussis (DTP). The outbreaks of pertussis have been reported periodically every two to five years [12]. In our study, there was an obvious increase in the numbers of patients and deaths in 2018-2019. This may be due to the increasing laboratory tests of pertussis in our hospital in the last two years. The mortality of severe pertussis has been reported to be very high in developed countries, ranging from $19.7-31 \%[13,14]$. The mortality of pertussis was $9.0 \%$ in our study, and the mortality of severe pertussis in the PICU/NICU was $34.2 \%$. The mortality of severe pertussis might be lower than that in reality because of the limitations of the laboratory tests and the inadequate recognition of this disease in its early stage. Some pertussis 
patients who died were not tested for $B$. pertussis and might be misdiagnosed. Previous reports have indicated that the mortality of pertussis in infants younger than 6 weeks was much higher [4]. In our study, $56.9 \%$ of patients aged $<3$ months died, $92.3 \%$ were younger than 3 months and $76.9 \%$ were younger than 6 weeks. This means that these children were not protected by the vaccine, because the recommended schedule for DTP vaccination is from 3 months of age in our country. In 2015, the WHO recommended that the primary DTP vaccination should be given at 6 weeks, at least not later than 2 months [3]. From the results of our research, we also recommend the first dose of DTP should advance to the age of 2 months or even 6 weeks in China.

Based on other publications, younger age, younger gestational age and lower birth weight were the risk factors for death $[15,16]$, and age $<3$ months and underlying comorbid conditions were the independent risk factors for death [17]. In our study, we identified that host factors such as younger age and lower birth weight were significantly associated with the death of patients with severe pertussis. However, it was an unexpected finding that younger age was not found to be an independent risk factor, likely because most of the pertussis patients in our study aged $<6$ months, especially those aged $<3$ months, would affect the data analyses, leading to bias om the result. On the other hand, we identified that clinical manifestations, such as fever $\geq 38.5^{\circ} \mathrm{C}$, cough $\geq 14$ days, cyanosis, shortness of breath, fatigue with feeding, seizures, altered sensorium, oxygen saturation $<90 \%$, increased respiratory rate, increased heart rate, crackles, and capillary filling time(CRT) $₫ 2 \mathrm{~s}$ were significantly associated with the death of severe pertussis patients. These factors would be some important hints to help paediatric doctors recognize severe pertussis patients in the early stage of the illness.

Severe pertussis that resulted in death was accompanied by a wide range of complications, such as pneumonia, pneumothorax, $\mathrm{PH}$, haemorrhage from the gastrointestinal or respiratory tract, toxic encephalopathy, and septic shock being the most reported [18-20]. In our study, the presence of pneumonia, pleural effusion, pneumothorax, respiratory failure, ARDS, pneumorrhagia, $\mathrm{PH}$, heart failure, sepsis, toxic encephalopathy, and acute renal failure were associated with death. Pneumonia was the most common complication in severe pertussis and was significantly associated with death $[18,20]$. All our cases of death were diagnosed as pneumonia by chest radiography, and patients tended to present with a more severe pneumonia patch or effusion, which was more likely to develop into ARDS or even pneumorrhagia. ARDS and pneumorrhagia were associated with death from severe pertussis in our univariable analysis, which coincides with prior evidence.

$\mathrm{PH}$ was present in only 12 patients in our study, but it was a strong predictor of death, as well as an independent risk factor for death. A previous study reported refractory PH in fatal pertussis, which is often associated with hyperleukocytosis [21]. In our study, the leucocytosis in one of patient who died exceeded $100 \times 10^{9} / \mathrm{L}\left(103.23 \times 10^{9} / \mathrm{L}\right)$. We identified that leucocytosis $>70.0 \times 10^{9} / \mathrm{L}$ and absolute lymphocyte count $>20 \times 10^{9} / \mathrm{L}$ were also significantly associated with the deaths of patients with severe pertussis, and leucocytosis $\left(>70.0 \times 10^{9} / \mathrm{L}\right)$ was an independent risk factor for death. The mechanism of PH and hyperleukocytosis occurred in severe pertussis due to pertussis toxin (PT) [18]. PT can affect cellular signalling and promote leucocytosis with lymphocytosis, which can result in a hyperviscosity syndrome 
[22]. Previous reports have shown that luminal aggregates of leucocytes have been observed in pulmonary arterioles, veins and lymphatics of post-mortem lung tissue from infants who died from pertussis [23]. Abnormal leucocyte aggregation in the lungs can diminish blood flow by increasing vascular resistance, which may lead to $\mathrm{PH}$ [24]. In addition, pertussis pneumonia may trigger hypoxia, acidosis, acute pulmonary vasoconstriction, microcirculation disturbances, and clotting dysfunction. All these compounded effects produce markedly elevated pressures in the vasculature of the lung that could trigger irreversible PH [24,25]. Meanwhile, PT is a known inhibitor of G-proteins, which are cardioprotective[26]. PT could alter the vagal control of the heart rate and respiratory rate through the regulation of G-proteins $[18,27]$. The rapid increase in heart and respiratory rates, which were associated with death in our cases. Future prospective studies are needed to assess the mechanism of severe pertussis.

The management of severe pertussis is extremely challenging, especially when accompanied by $\mathrm{PH}$ and hyperleukocytosis. Most of the patients received macrolide treatments, and some severe patients received immunoglobulin therapy. Previous literature has reported that using inhalation of $\mathrm{NO}$ to treat neonatal $\mathrm{PH}$ can significantly shorten treatment time and reduce mortality [28]. However, in our study, PH did not improve in four infants who received inhalation of NO. The traditional approach to reduce pulmonary vascular resistance, such as inhalation of NO, may fail because of hyperviscosity and vascular obstruction [22]. Our data suggest that inhalation of NO may not be useful in pertussis-related PH but more samples are needed to confirm this hypothesis. Exchange blood transfusion, which is frequently conducted in the NICU, was first published in a patient with severe pertussis[29]; thereafter, exchange blood transfusion has been reported in multiple case series and case reports of severe pertussis to reduce the level of the total leucocyte count[13,18,22]. In our study, 11 patients with severe pertussis in the PICU/NICU underwent exchange blood transfusion, eight patients survived and three died. Exchange blood transfusion can reduce the levels of the leucocytosis and thrombosis in patients with severe pertussis, thereby improving the severity of $\mathrm{PH}$. In addition, two patients who underwent exchange blood transfusion in the early stages of disease also underwent ECMO therapy when exchange blood transfusion did not seem to work. One patient survived, while the other died because of refractory heart failure and septic shock. The use of ECMO in severe pertussis has been reported with some success in small series $[18,22,30]$, with a survival rate of only $30 \%$, and the mortality remains higher than that for other indications for $\mathrm{ECMO}^{30}$. Further and larger prospective studies are urgently needed to confirm the critical time of exchange blood transfusion and to define the optimal use of ECMO in severe pertussis in order to decrease its mortality.

\section{Conclusions}

In our study, severe pertussis mainly occurred in children aged $<3$ months, and most of the patients were unvaccinated with regard to pertussis. The mortality of severe pertussis was $34.2 \%$, with the severe patients younger than 6 weeks accounting for the majority of deaths $(76.9 \%)$. We recommend the first dose of DTP should advance to the age of 2 months or even 6 weeks. The presence of WBC $>70.0 \times 10^{9} / \mathrm{L}$ 
and $\mathrm{PH}$ were the prognostic variables independently associated with death. Our data also suggest that inhalation of NO may not be useful in pertussis-related $\mathrm{PH}$.

\section{Abbreviations}

ARDS: Acute Respiratory Distress Syndrome; BAL: Bronchoalveolar Lavage; CRRT: Continuous Renal Replacement Therapy; CRT: Capillary Filling Time; DTP: Diphtheria-Tetanus-Pertussis; ECHO:

Echocardiography; ECMO: Extracorporeal Membrane Oxygenation; ERS: European Respiratory Society; ESC: European Society of Cardiology; HRCT High-resolution Computed Tomography; IQR: Interquartile Range; NICU: Neonatal Intensive Care Unit; PCR: Polymerase Chain Reaction; PH: Pulmonary Hypertension; PICU: Paediatric Intensive Care Unit; PT: Pertussis Toxin; NO: Nitric Oxide

\section{Declarations}

\section{Acknowledgements}

We would like to thank all patients and their families involved in this study.

\section{Authors' contributions}

TS, LW and GL designed the study and wrote the manuscript. HF, MY,XX and DZ gathered the data. Material preparation and data analysis were performed by SD, DT and LH. All authors contributed to the review and revision of the manuscript and have read and approved the final version.

\section{Funding}

Not applicable.

\section{Availability of data and materials}

The Author confirms that the data supporting the findings of this study are available within the article. More information that supports the findings of this study is available from the corresponding author GL, upon reasonable request.

\section{Ethics approval and consent to participate}

This study was approved by the Ethics Committee of Guangzhou Women and Children's Medical Centre, Guangzhou Medical University[approval number: [2020]63701].Written informed consent to participate in this study was obtained from their parents/guardians.

\section{Consent for publication}

Not applicable. 
Competing interests

The authors declare that they have no competing interests.

Author details

${ }^{1}$ Department of Respiratory, Guangzhou Women and Children's Medical Center, Guangzhou Medical University, Guangzhou, China. ${ }^{2}$ Department of Neonatology, Guangzhou Women and Children's Medical Center, Guangzhou Medical University, Guangzhou, China. ${ }^{3}$ Key Laboratory of Tropical Disease Control, Ministry of Education, Sun Yat-sen University, Guangzhou, China. ${ }^{4}$ Department of Cardiology, Guangzhou Women and Children's Medical Center, Guangzhou Medical University, Guangzhou, China. ${ }^{5}$ Pediatric Intensive Care Unit, Guangzhou Women and Children's Medical Center, Guangzhou Medical University, Guangzhou, China.

\section{References}

1. Yeung KHT, Duclos P, Nelson EAS, Hutubessy RCW: An update of the global burden of pertussis in children younger than 5 years: a modelling study. Lancet Infect Dis 2017, 17(9):974-980.

2. Cherry JD: The epidemiology of pertussis: a comparison of the epidemiology of the disease pertussis with the epi demiology of Bordetella pertussis infection. Pediatrics 2005, 115(5):1422-1427.

3. Pertussis vaccines: WHO position paper - September 2015. Wkly Epidemiol Rec 2015, 90(35):433458.

4. Pierce $\mathrm{C}$, Klein N, Peters M: Is leukocytosis a predictor of mortality in severe pertussis infection? Intensive Care Med 2000, 26(10):1512-1514.

5. Su QR, Deng JK: [Children's pertussis immunization strategy in China]. Zhonghua er ke za zhi = Chinese journal of pediatrics 2020, 58(7):615-617.

6. Berger JT, Carcillo JA, Shanley TP, Wessel DL, Clark A, Holubkov R, Meert KL, Newth CJ, Berg RA, Heidemann $S$ et al: Critical pertussis illness in children: a multicenter prospective cohort study. Pediatr Crit Care Med 2013, 14(4):356-365.

7. Gali ${ }^{\cdots}$ N, Humbert M, Vachiery JL, Gibbs S, Lang I, Torbicki A, Simonneau G, Peacock A, Vonk Noordegraaf A, Beghetti $\mathrm{M}$ et al: 2015 ESC/ERS Guidelines for the diagnosis and treatment of pulmonary hypertension: The Joint Task For ce for the Diagnosis and Treatment of Pulmonary Hypertension of the European Society of Cardiology (ESC) and the European Respiratory Society (ERS): Endorsed by: Association for European Paediatric an d Congenital Cardiology (AEPC), International Society for Heart and Lung Transplantation (ISHLT). Eur Respir J 2015, 46(4):903-975.

8. Goldstein B, Giroir B, Randolph A, International Consensus Conference on Pediatric S: International pediatric sepsis consensus conference: definitions for sepsis and organ dysfunction in pediatrics. Pediatr Crit Care Med 2005, 6(1):2-8. Pediatric Acute Lung Injury Consensus Conference G: 
9. Pediatric acute respiratory distress syndrome: consensus recommendations from the Pediatric Acute Lun g Injury Consensus Conference. Pediatr Crit Care Med 2015, 16(5):428-439.

10. Cortese MM, Baughman AL, Zhang R, Srivastava PU, Wallace GS: Pertussis hospitalizations among infants in the United States, 1993 to 2004. Pediatrics 2008, 121(3):484-492.

11. Heininger U: [Pertussis (whooping cough)]. Monatsschr Kinderheilkd 2020:1-12.

12. Broutin $\mathrm{H}$, Viboud $\mathrm{C}$, Grenfell $B T$, Miller MA, Rohani P: Impact of vaccination and birth rate on the epidemiology of pertussis: a comparative study in 64 coun tries. Proc Biol Sci 2010, 277(1698):32393245 .

13. Kazantzi MS, Prezerakou A, Kalamitsou SN, llia S, Kalabalikis PK, Papadatos J, Sdougka MM, Briassoulis G, Tsolia MN: Characteristics of Bordetella pertussis infection among infantsand children admitted to paediatric in tensive care units in Greece: A multicentre, 11-year study. J Paediatr Child Health 2017, 53(3):257-262.

14. Burr JS, Jenkins TL, Harrison R, Meert K, Anand KJ, Berger JT, Zimmerman J, Carcillo J, Dean JM, Newth CJ et al: The Collaborative Pediatric Critical Care Research Network Critical Pertussis Study: collaborative re search in pediatric critical care medicine. Pediatr Crit Care Med 2011, 12(4):387-392.

15. Bettinger JA, Halperin SA, De Serres G, Scheifele DW, Tam T: The effect of changing from whole-cell to acellular pertussis vaccine on the epidemiology of hospital ized children with pertussis in Canada. Pediatr Infect Dis J 2007, 26(1):31-35.

16. Winter K, Harriman K, Zipprich J, Schechter R, Talarico J, Watt J, Chavez G: California pertussis epidemic, 2010. J Pediatr 2012, 161(6):1091-1096.

17. Chong CY, Yung CF, Tan NW, Acharyya S, Thoon KC: Risk factors of ICU or high dependency requirements amongst hospitalized pediatric pertussis cases: A 10 year retrospective series, Singapore. Vaccine 2017, 35(47):6422-6428.

18. Winter K, Zipprich J, Harriman K, Murray EL, Gornbein J, Hammer SJ, Yeganeh N, Adachi K, Cherry JD: Risk Factors Associated With Infant Deaths From Pertussis: A Case-Control Study. Clin Infect Dis 2015, 61(7):1099-1106.

19. Gopal DP, Barber J, Toeg D: Pertussis (whooping cough). Bmj 2019, 364:1401.

20. Haberling DL, Holman RC, Paddock CD, Murphy TV: Infant and maternal risk factors for pertussisrelated infant mortality in the United States, 1999 to 2004. Pediatr Infect Dis J 2009, 28(3):194-198.

21. Goulin GD, Kaya KM, Bradley JS: Severe pulmonary hypertension associated with shock and death in infants infected with Bordetella per tussis. Crit Care Med 1993, 21(11):1791-1794.

22. Straney L, Schibler A, Ganeshalingham A, Alexander J, Festa M, Slater A, MacLaren G, Schlapbach LJ, Australian, New Zealand Intensive Care Society Centre for $\mathrm{O}$ et al: Burden and Outcomes of Severe Pertussis Infection in Critically III Infants. Pediatr Crit Care Med 2016, 17(8):735-742.

23. Cherry JD, Paddock CD: Pathogenesis and histopathology of pertussis: implications for immunization. Expert Rev Vaccines 2014, 13(9):1115-1123. 
24. Paddock CD, Sanden GN, Cherry JD, Gal AA, Langston C, Tatti KM, Wu KH, Goldsmith CS, Greer PW, Montague $\mathrm{JL}$ et al: Pathology and pathogenesis of fatal Bordetella pertussis infection in infants. Clin Infect Dis 2008, 47(3):328-338.

25. Carbonetti NH: Pertussis leukocytosis: mechanisms, clinical relevance and treatment. Pathog Dis 2016, 74(7).

26. DeGeorge BR, Gao E, Boucher M, Vinge LE, Martini JS, Raake PW, Chuprun JK, Harris DM, Kim GW, Soltys $S$ et al: Targeted inhibition of cardiomyocyte Gi signaling enhances susceptibility to apoptotic cell death in response to ischemic stress. Circulation 2008, 117(11):1378-1387.

27. Adamson PB, Hull SS, Vanoli E, De Ferrari GM, Wisler P, Foreman RD, Watanabe AM, Schwartz PJ: Pertussis toxin-induced $A D P$ ribosylation of inhibitor $\mathrm{G}$ proteins alters vagal control of heart rate i $\mathrm{n}$ vivo. Am J Physio/ 1993, 265(2 Pt 2):H734-740.

28. Wu HW, Li ZG, Liu G, Lu GZ, Liang HY: Effect of nitric oxide inhalation for the treatment of neonatal pulmonary hypertension. Eur Rev Med Pharmacol Sci 2016, 20(21):4607-4611.

29. Romano MJ, Weber MD, Weisse ME, Siu BL: Pertussis pneumonia, hypoxemia, hyperleukocytosis, and pulmonary hypertension: improvement in oxygena tion after a double volume exchange transfusion. Pediatrics 2004, 114(2):e264-266.

30. Rowlands HE, Goldman AP, Harrington K, Karimova A, Brierley J, Cross N, Skellett S, Peters MJ: Impact of rapid leukodepletion on the outcome of severe clinical pertussis in young infants. Pediatrics 2010, 126(4):e816-827.

\section{Figures}




\section{Age distributions}

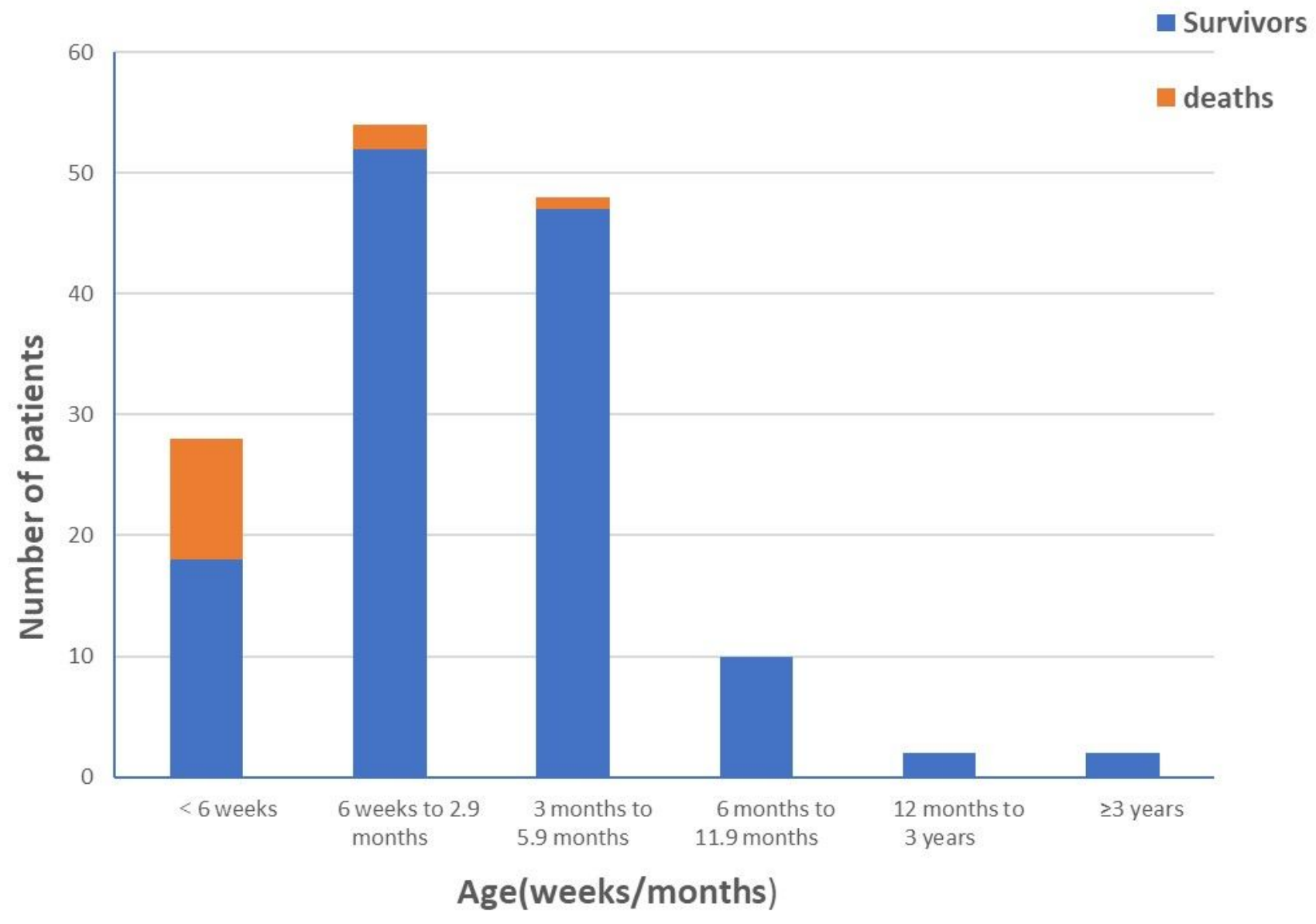

Figure 1

Age distribution of the children with pertussis 


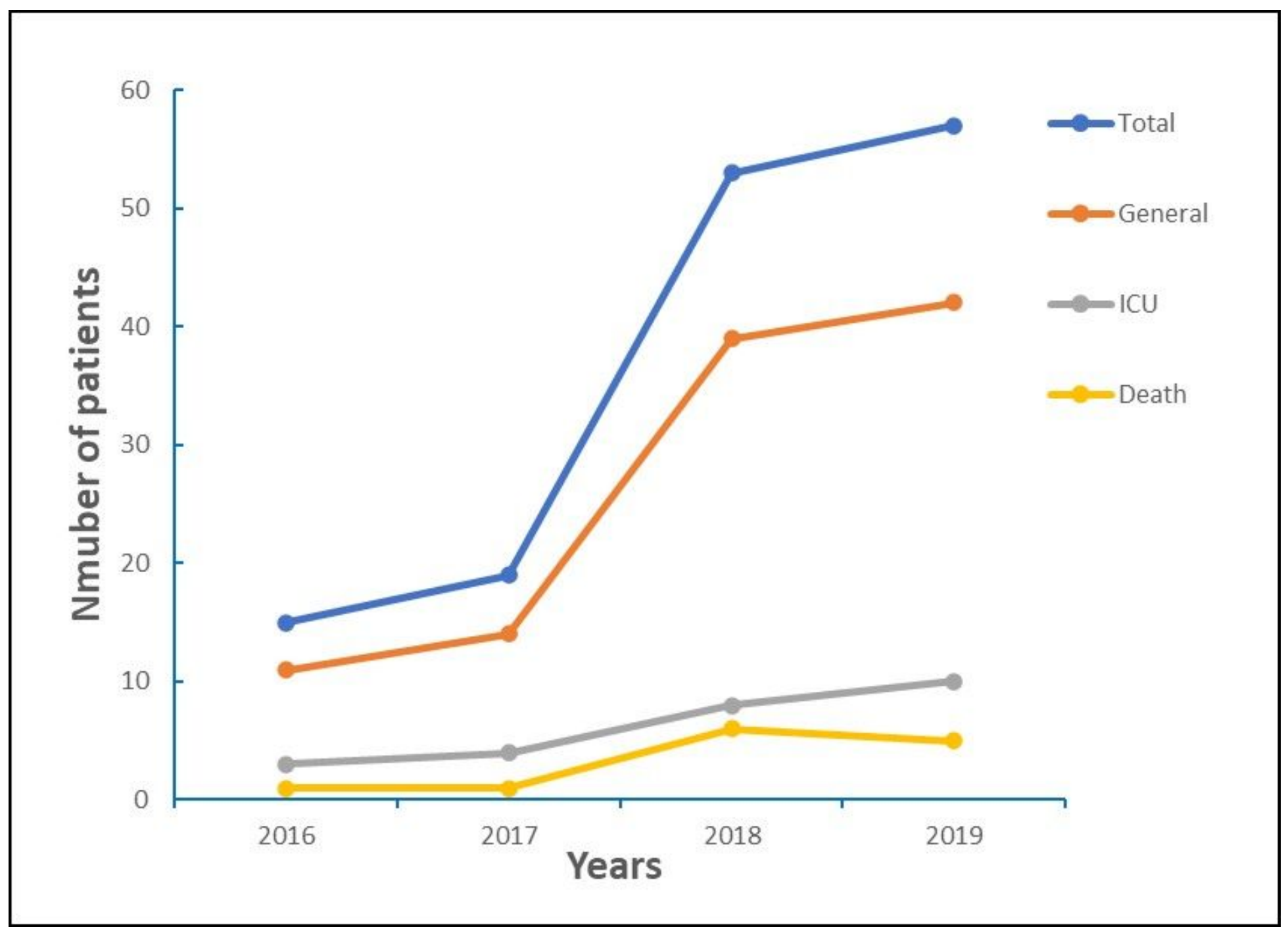

Figure 2

Distribution of the number of pertussis patients per year 


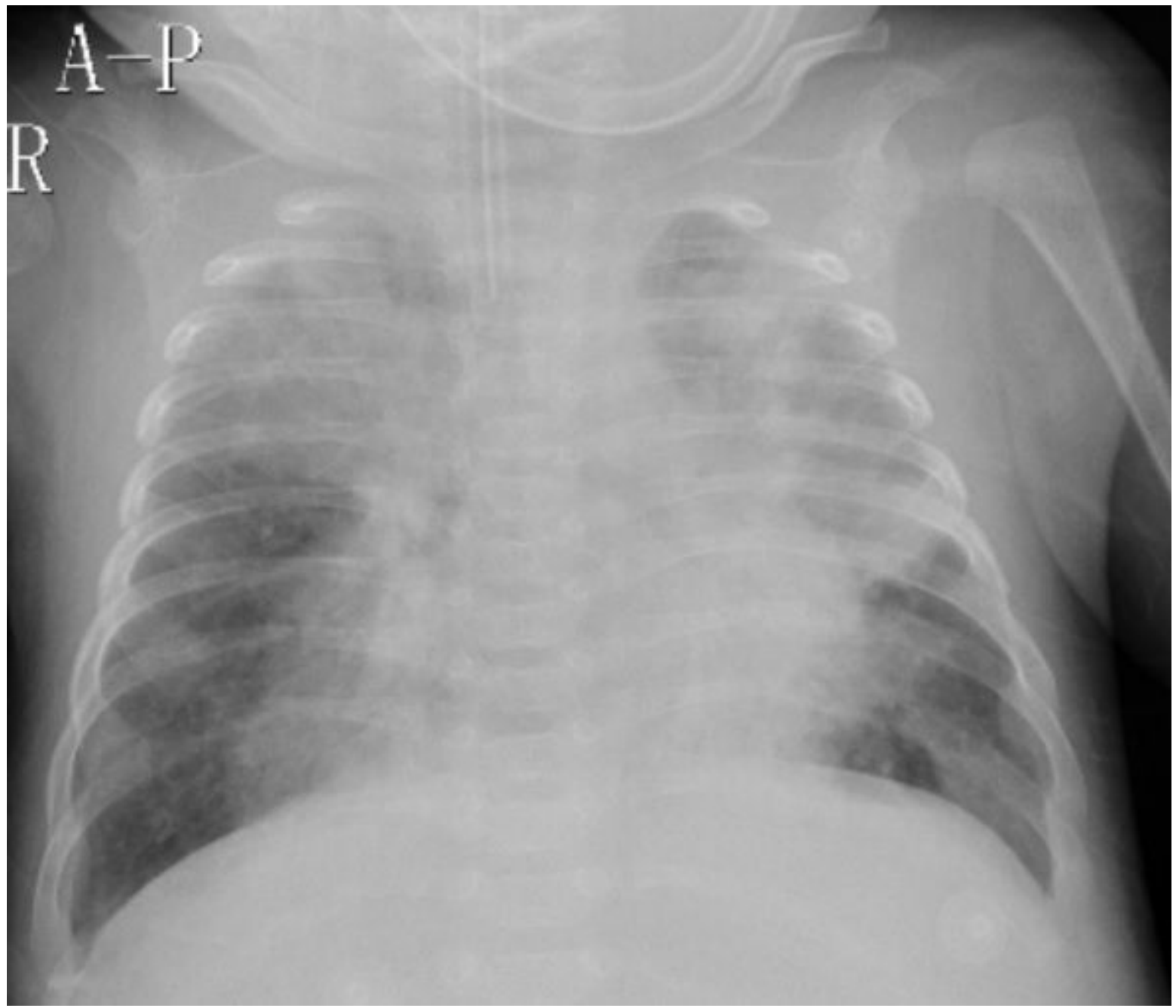

Figure 3

Chest radiograph showing bilateral diffuse infiltration and upper lungs are prominent indicative of acute respiratory distress syndrome.
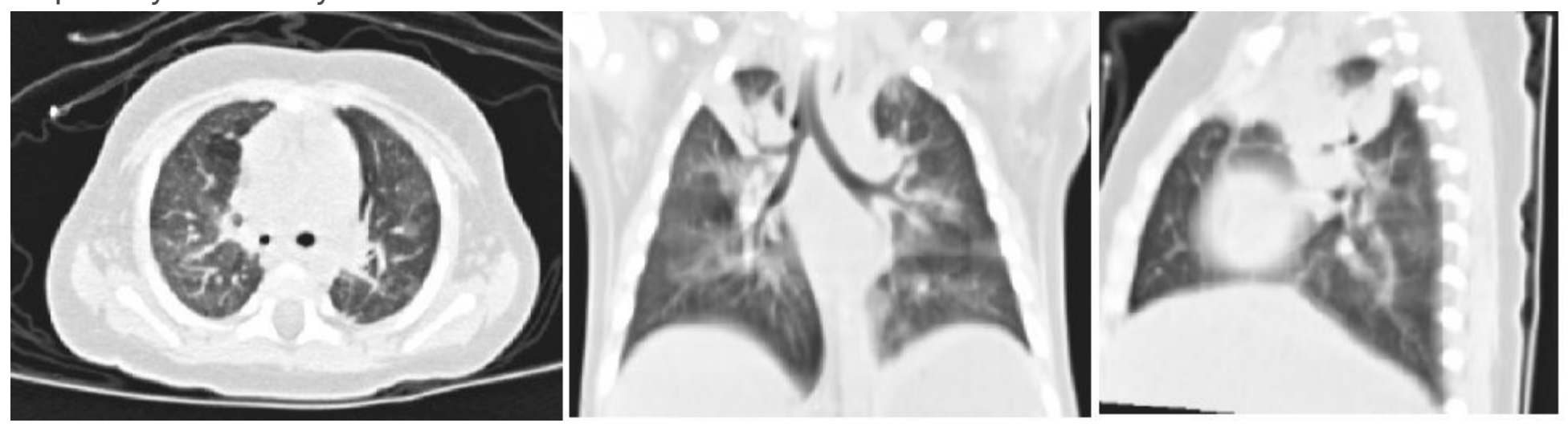

Figure 4

High-resolution CT scan of the chest revealing diffuse infiltration and areas of consolidation in the right upper in a four-month-old girl. 


\section{Supplementary Files}

This is a list of supplementary files associated with this preprint. Click to download.

- Rawdataofmildcases.xlsx

- Rawdataofseverecasesdeath.xlsx

- Rawdataofseverecasessurvival.xIsx 